\title{
Transsacral transdiscal L5-S1 screws for the management of high-grade spondylolisthesis in an adolescent
}

\author{
Ali Palejwala, BS, ${ }^{1,2}$ Jared Fridley, MD,,2 and Andrew Jea, MD ${ }^{1,2}$ \\ 'Division of Pediatric Neurosurgery, Texas Children's Hospital; and 'Department of Neurosurgery, Baylor College of Medicine, \\ Houston, Texas
}

\begin{abstract}
The surgical management of high-grade spondylolisthesis in adolescents remains a controversial issue. Because the basic procedure, posterolateral fusion, is associated with a significant rate of pseudarthrosis and listhesis progression, there is a pressing need for alternative surgical techniques. In the present report, the authors describe the case of an adolescent patient with significant low-back pain who was found to have Grade IV spondylolisthesis at L5-S1 that was treated with transsacral transdiscal screw fixation. Bilateral pedicle screws were placed starting from the top of the S-1 pedicle, across the L5-S1 intervertebral disc space, and into the L-5 body. At 14 months after surgery, the patient had considerable improvement in his pain and radiographic fusion across L5-S1. The authors conclude that transsacral transdiscal pedicle screws may serve as an efficacious and safe option for the correction of high-grade spondylolisthesis in adolescent patients.
\end{abstract}

http://thejns.org/doi/abs/10.3171/2015.12.PEDS15535

KEY WORDS adolescent spine; spondylolisthesis; transsacral screw

$\mathrm{S}$ PONDYLOLISTHESIS is a common cause of structural back pain in children and adolescents. According to Wiltse et al., ${ }^{43}$ it can be classified as dysplastic/ congenital (Type I), isthmic (Type II), degenerative (Type III), traumatic (Type IV), or pathological (Type V). Of these, pediatric/adolescent spondylolisthesis mainly results from a congenital malformation at L5-S1 (Type I) or stress fracture of the pars interarticularis (Type II). These defects, most commonly found in the lumbosacral spine, result in mechanical instability that can cause forward slippage of one vertebra over another. To quantify the deformity, the Meyerding system ${ }^{25}$ which measures the proportional anterior displacement of a vertebra, assigns the slip as Grade I (0\%-25\%), Grade II (25\%-50\%), Grade III (50\%-75\%), or Grade IV (75\%-100\%). The angle of lumbosacral kyphosis (slip angle), which measures the angular displacement of L-5 on S-1, is also used. High-grade spondylolisthesis is defined as Grade III-IV (more than $50 \%$ slippage).

Based on recommendations from Wiltse and Jackson, ${ }^{42}$ indications for surgical management in the pediatric and adolescent population include the following: persistence of neurological symptoms despite nonoperative management; progressive slippage beyond 25\%-33\%; highgrade spondylolisthesis (Grade III-IV); and observation of postural or gait deformities. The majority of patients with high-grade spondylolisthesis are managed surgically; however, there is controversy with regard to the optimal surgical technique. The goals in surgical correction of high-grade spondylolisthesis are to arrest the progression of listhesis, achieve decompression of neural elements, and maintain the slip angle, which contributes to postural and gait abnormalities.

The basic procedure used to correct spondylolisthesis is posterolateral fusion. In the pediatric/adolescent population, a high rate of fusion is generally achieved with this approach, but the rate of pseudarthrosis may be higher. Surgical techniques, including circumferential $360^{\circ} \mathrm{fu}$ sion, have been developed to create a more durable fusion construct. However, the morbidity associated with these techniques may be higher and the techniques do not necessarily lead to a better functional outcome ${ }^{20}$ Reduction methods have gained popularity due to their ability to correct the kyphotic slip angle into lordosis and establish rigid

ABBREVIATIONS BMP = bone morphogenetic protein; MCID = minimal clinically important difference; ODI = Oswestry Disability Index; SRS-22 = Scoliosis Research

Society-22.

SUBMITTED August 31, 2015. ACCEPTED December 2, 2015.

INCLUDE WHEN CITING Published online February 19, 2016; DOI: 10.3171/2015.12.PEDS15535. 
fixation to avoid pseudarthrosis. ${ }^{44}$ Yet this has been met with concern, as reductive techniques have also been associated with a higher risk of neurological injury, with rates as high as $25 \%-30 \%{ }^{8}$

Thus, we must investigate safe and effective alternative techniques in the treatment of high-grade spondylolisthesis. Herein, we describe the case of an adolescent patient with high-grade spondylolisthesis treated with transsacral transdiscal screw fixation, an alternative technique for treating this disorder.

\section{Case Report}

History and Presentation

A 12-year-old boy with no prior medical history presented after 1 year of low-back pain that had worsened over the past month. A neurological examination demonstrated normal strength, sensation, and reflexes.

Lumbosacral radiographs revealed Grade IV L5-S1 spondylolisthesis with a slip angle of $10^{\circ}$ (Fig. 1). CT scanning of the lumbar spine demonstrated bilateral spondylolysis at L-5. MRI showed stenosis of the bilateral L5-S1 neural foramina, along with degenerative disc disease at L4-5 and L5-S1 (Fig. 1).

Because of the patient's progressive back pain and risk of deformity progression, he was offered surgical intervention. The patient's parents had initially decided to pursue conservative management with a lumbosacral orthotic, despite understanding the risk of disease progression. However, the patient's functional status deteriorated, with increasing back pain, bilateral radicular pain leg, and development of a toe-walking gait. Bowel and bladder function seemed preserved. After 12 months of failed conservative management, the patient underwent surgical intervention.

\section{Operation}

Surgery was planned to stabilize the spine in situ and to decompress the neural elements (L-5 and sacral nerve roots) at the lumbosacral junction. After administration of general anesthesia, needle electrodes were placed in the upper and lower extremities for somatosensory evoked potentials (SSEPs) and electromyography (EMG), respectively. The patient was then turned prone onto a Wilson frame. A midline skin incision was performed to expose the posterior elements from L-3 to S-1 in the standard subperiosteal fashion.

Using the standard entry point for $\mathrm{S}-1$ pedicle screws, a pedicle finder and tap under fluoroscopic guidance were passed successively from the S-1 vertebral body through the L5-S1 disc space and then into the L-5 vertebral body. A $6.5 \times 60-\mathrm{mm}$ pedicle screw (Solera, Medtronic Sofamor Danek) was implanted. The same procedure was repeated on the other side to stabilize the slip between L-5 and S-1. Bilateral L-4 $5.5 \times 40-\mathrm{mm}$ pedicle screws (Solera) were then placed.

A Gill decompressive procedure was performed at L-5. This decompression entailed excision of the loose L-5 lamina, removal of the fibro-cartilaginous plugs at the pars defects, division of the adhesions between the dura and ligamentum flavum, and dissection of the L-5
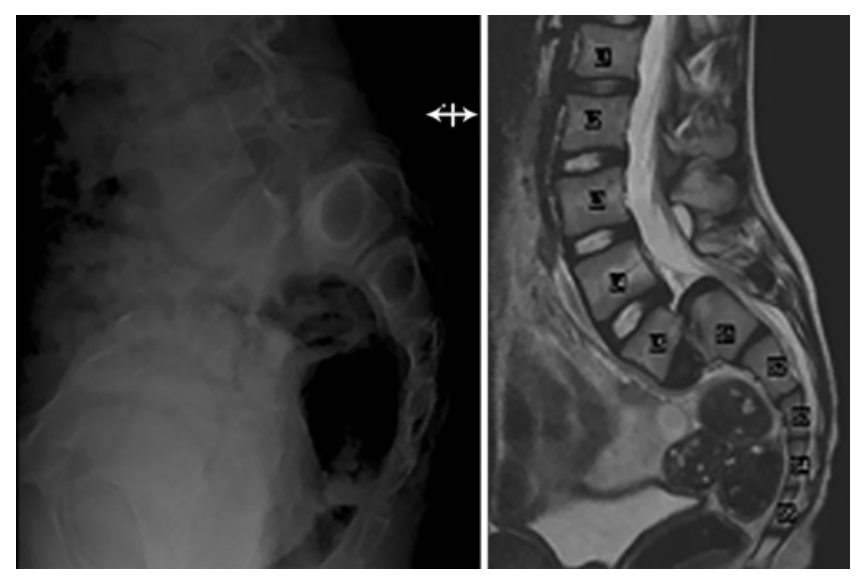

FIG. 1. Left: Preoperative lumbar spine radiograph demonstrating nearly complete spondylolisthesis of L-5 on S-1. Right: Preoperative lumbar spine MRI demonstrating degenerative discopathy at L4-5 and L5-S1.

nerve roots, as they course through the intervertebral foramen. Final rods were placed; the exposed bony surfaces were decorticated; and morselized autograft from the L-5 lamina and spinous process $(8.0 \mathrm{mg}$ in a large kit of bone morphogenetic protein [BMP; Infuse, Medtronic Sofamor Danek]) was used as graft material.

\section{Postoperative Course}

After surgery, the patient was placed in a thoracolumbosacral orthosis with hip extensions. Lumbosacral radiographs, as well as CT of the lumbar spine, confirmed proper placement of spinal hardware (Fig. 2). The patient was discharged on postoperative Day 7.

At 14 months after surgery, the patient reported significant improvement in his back pain, leg pain, and gait. Before surgery, he had recorded an Oswestry Disability Index (ODI) of 30; at the most recent follow-up, the patient reported an ODI of 13 , representing significant improvement, assuming the minimal clinically important difference (MCID) to be 12.8-15 points. . $^{13,15,17}$ Likewise, prior to surgery, the patient had reported a Scoliosis Research Society-22 (SRS-22) score of 3.73. After surgery, at the most recent follow-up, he reported an SRS-22 score of 4.73 , indicating a satisfactory outcome from surgery, assuming the MCID to be $0.4-0.6^{2,16}$ Dynamic lumbosacral spine radiographs and CT scans of the lumbosacral spine (Fig. 3) demonstrated solid bony fusion and no evidence of hardware failure or pseudarthrosis. The patient noticed some transient urinary dribbling for 6 months after surgery; since then, there have been no further symptoms of bladder dysfunction. Formal urological examination findings, including renal ultrasound results, were normal.

\section{Discussion}

Isthmic spondylolisthesis is a common cause of structural back pain in children and adolescents. It occurs most frequently at L5-S1 and, to a lesser degree, at L4-5. The incidence of isthmic spondylolisthesis is $4.4 \%-5.0 \%$ at age 5-7 years, increasing to $6 \%$ at age 18 years. ${ }^{14}$ Highgrade spondylolisthesis comprises about $5 \%$ of these total cases ${ }^{35}$ making it a relatively uncommon condition in ado- 


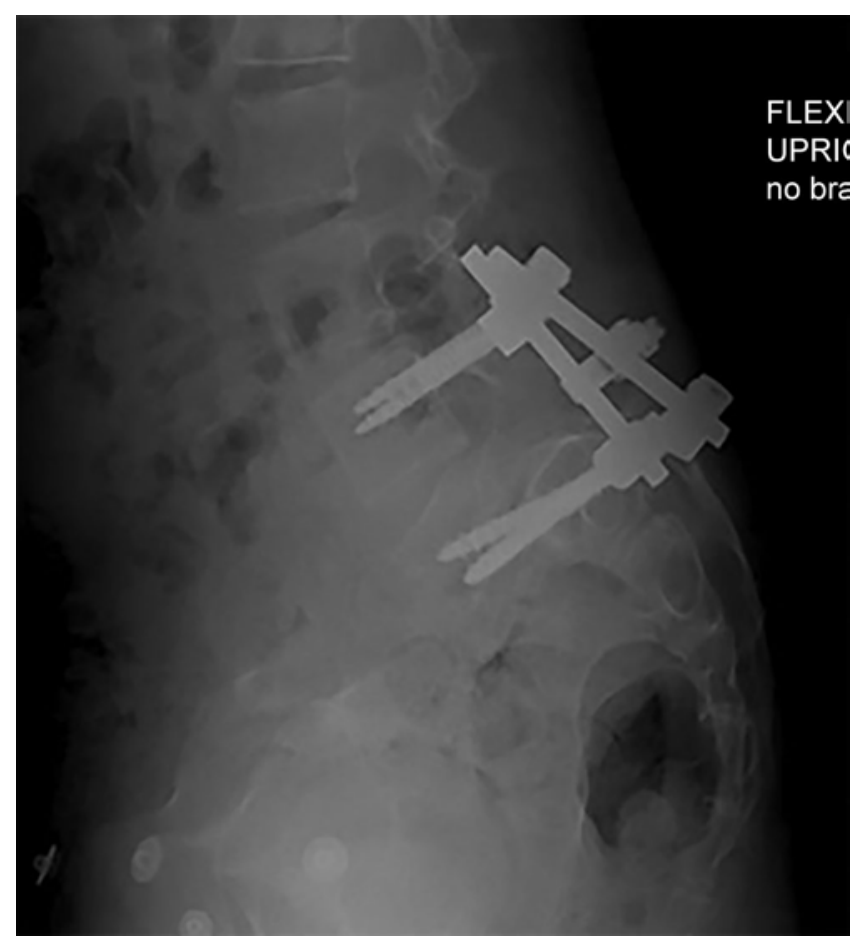

FIG. 2. Postoperative lumbar spine radiograph demonstrating stable hardware. Alignment is unchanged.

lescence. Although the male-to-female ratio of incidence is approximately $2: 1,7$ adolescent females seem to have a stronger tendency to develop high-grade slips (Reynolds JB, Banta C, Wiltse LL: High-grade spondylolisthesis in the young: a long-term follow up of in situ fusion. Paper presented at the 59th Annual Meeting of the American Association of Orthopaedic Surgeons, Washington, DC, February 20-25, 1992). Other risk factors that have been identified include having first-degree relatives with slippage, ${ }^{29}$ occult spina bifida at $\mathrm{S}-1,{ }^{19}$ and the presence of scoliosis. ${ }^{30}$

\section{Clinical Features}

The clinical manifestations of high-grade spondylolisthesis are variable. Many patients are asymptomatic. Symptomatic patients typically present with low-back pain, radiculopathic pain, motor/sensory deficits in the lower extremities, or bowel/bladder dysfunction. The severity of back pain has not been shown to correlate with degree of slippage. ${ }^{22}$ Symptomatic patients usually present around adolescence, ${ }^{10}$ when skeletal immaturity, rapid growth rate, and a tendency to participate in competitive sports create gravitational and postural forces that focus at the pars interarticularis ${ }^{31}$ and exacerbate the instability. Since lumbosacral kyphosis increases as slippage becomes high-grade spondylolisthesis, compensatory pelvic retroversion causes the sacrum to become more vertical. This can manifest as an abnormal toe-walking gait due to hip flexion and compensatory knee flexion used to maintain an upright posture. Palpation of the lower back can demonstrate a noticeable spinous process step-off at the affected level.
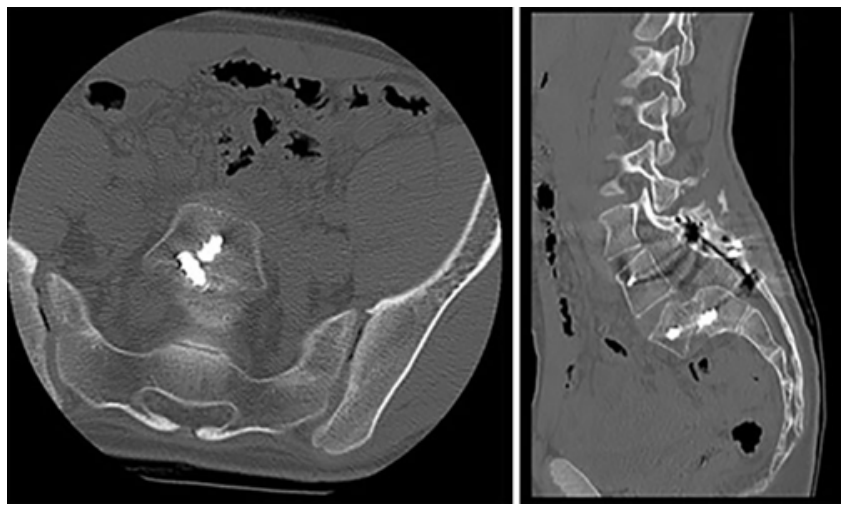

FIG. 3. Left: Axial CT scan obtained at the level of L-5 showing bilateral crossing transsacral transdiscal screws. Right: Parasagittal CT scan of the lumbosacral junction demonstrating solid bony fusion across the L5-S1 disc space anteriorly and L-4 to S-1 posteriorly.

\section{Surgical Techniques}

The goals for surgical correction of high-grade spondylolisthesis are to arrest the progression of listhesis, achieve decompression of neural elements, and prevent a worsening slip angle. Our surgical philosophy for high-grade spondylolisthesis has been to obtain an in situ fixation of the spine.

Any reductive technique of high-grade spondylolisthesis is controversial. Multiple methods exist by which to reduce listhesis. ${ }^{33}$ When reduction is performed, the rate of pseudarthrosis is decreased. When using interbody devices, reduction allows a larger endplate surface area for contact with the graft to occur, which likely increases fusion rates, as well as decreases tensile forces of the graft.

Bouyer et al. ${ }^{6}$ reported treating 12 pediatric patients with high-grade spondylolisthesis by performing a circumferential fusion at L4-5 and L5-S1 combined with reduction using a transsacral rod. The end point of reduction was correction of lumbosacral kyphosis. This method achieved statistically significant improvement in the degree of slippage in patients. However, 5 of the 12 patients reported transient neurological deficits. Bollini et al. ${ }^{4}$ described a method using a 10 -mm cannulated screw inserted from the posterior aspect of S-2 to the anterosuperior aspect of $\mathrm{L}-5$. This required removal of the $\mathrm{L}-5, \mathrm{~S}-1$, and S-2 posterior neural arches to dissect the neural elements, along with L5-S1 discectomy and posterior circumferential fusion. Surgery was lengthy, lasting a mean of 285 minutes, and 1 patient sustained permanent neurological deficit at L-5.

A number of other authors have compared pediatric patients with high-grade spondylolisthesis treated with fusion alone versus those treated with reduction and fusion. ${ }^{26,27,32}$ All reported that although fusion and reduction achieve a higher rate of fusion, this does not necessarily lead to better clinical or functional outcomes. In patients with significant gait deformity, advocates of reduction often argue that reduction helps to alleviate compensatory postural changes, indirectly decompresses neural foramina, and decreases mechanical strain that leads to chronic back pain. However, there are significant risks to reduction maneuvers, including neurological injury. These include 
applying direct pressure to the nerve root during decortication of bone, extradural forces on the nerve roots during reduction, and disc material extruding into the spinal canal. ${ }^{44}$ Patients may present with dysesthesias in a dermatomal distribution or motor deficits.

Therefore, there is a need to investigate safer techniques for the treatment of high-grade spondylolisthesis. Intertransverse in situ fusion for spondylolisthesis was first described by Watkins in $1952 .{ }^{41}$ However, other studies have raised concerns that this method has a significant rate of pseudarthrosis. ${ }^{5,7}$ In 1955, Bosworth et al..$^{5}$ reported a pseudarthrosis rate of $15 \%$ on long-term follow-up. Moreover, despite solid arthrodesis and maturation of the fusion mass, slippage may progress postoperatively, leading to a persistence of the lumbosacral deformity and leaving patients with a residual cosmetic deformity. This can be explained through a biomechanical standpoint, as the fusion mass is subject to tensile forces exaggerated through nonphysiological alignment of the spine.

Fusion rates have been improved when combined with anterior techniques. As the intervertebral disc space offers a bed for fusion, anterior lumbar interbody fusion may be performed with autograft, allograft, or synthetic cages. This technique confers the theoretical advantage of anterior support and increased construct strength, as this fusion mass is under compression force rather than tension. Anterior lumbar interbody fusion is best combined with posterolateral fusion, creating a circumferential $360^{\circ}$ fusion. From a biomechanical standpoint, this approach is superior in that it offers 3-column stabilization of the spine. Nonetheless, circumferential $360^{\circ}$ fusion involves 2 operations, adding to the surgical risk and patient morbidity.

The Bohlman technique attempted to address the shortcomings of an additional anterior approach by providing a circumferential fusion through a single-stage posterior-only approach. This procedure involved a posterior decompression, posterolateral fusion using autologous bone graft (iliac crest), and anterior oblique interbody fusion with an autologous bone graft (fibular). Its theoretical benefit was that when the fibular bone dowel is inserted obliquely (transsacral), there is an increased surface area for graft incorporation; this confers a stabilizing effect with respect to slippage. In 11 skeletally mature patients with high-grade spondylolisthesis, the Bohlman technique was performed without any attempt to correct the deformity. ${ }^{39}$ Concerns about this procedure include the presence of late failure of the bone dowel. Modifications of the Bohlman technique have been reported to augment the strength of the construct with posterior pedicle screw instrumentation.

The procedure used in the patient in our case is a modification of the Bohlman procedure. We performed a standard Gill decompression; however, there is controversy in the orthopedic spine literature whether a decompression needs to be performed at all. ${ }^{11}$ Perhaps the elimination of the dynamic "guillotine" effect with a fusion alone is sufficient to improve clinical outcomes and neurological symptoms. In this technique, bilateral L-4 pedicle screws are inserted. The fusion is extended to the L-4 transverse process to provide a larger surface area for the fusion mass, due to the small surface area at the L-5 transverse process in children..$^{12}$ Then, S-1 pedicle screws are inserted anteromedially through the $\mathrm{S}-1$ pedicle into the sacral promontory and superior endplate of S-1, ending in the midline of the displaced L-5 vertebral body inferior endplate. This technique avoids the risk of L-5 nerve root injury by placing pedicle screws into the anteriorly displaced L-5 pedicles. By passing through 2 vertebrae, 4 cortical surfaces are captured and the pullout strength of the screw is increased. The anteromedial triangulation of the screw insertion increases the construct's stability. While we used only fluoroscopic guidance in placing our L-4 pedicle screws and transsacral screws, there may be a role for computerized image guidance and advanced intraoperative spinal imaging, such as new-generation intraoperative CT scanners, which have been validated in terms of giving accurate pedicle screw position information. $1,18,21,23,24,28,34,36,38,40$

To increase the chance of a solid and successful fusion, BMP was used to supplement local autograft. Discussion with patients and their caregivers on the potential risks of BMP, including the risk of future cancer, was performed as part of the surgical consent process. The most serious concern with the use of BMP has been the potential to affect processes regulating cell division; consequently, it may contribute to tumorigenesis, tumor degeneration, and metastasis. However, BMP has the benefits of decreased operative time, blood loss, donor site morbidity, transmission of infection associated with use of allograft, and rate of pseudarthrosis. ${ }^{3,9}$ In a retrospective analysis of 47 patients conducted at our institution, the use of BMP in pediatric patients undergoing occipitocervical, cervical, and thoracic, lumbar, or lumbosacral spine fusion led to no cases of new cancers, tumor degeneration, or metastasis at the 24-month follow-up. ${ }^{37}$

To the best of our knowledge, no other studies have been published reporting the use of transsacral pedicle screws in adolescents with high-grade spondylolisthesis. This construct confers the advantage of stable 3-column stabilization through a simple and safe construct. When attempted in our case, the procedure did not lead to any neurological deficits. The patient in our report demonstrated low-back pain, bilateral radicular pain, and a toewalking gait consistent with high-grade spondylolisthesis. At 14 months after surgery, the patient has experienced relief from these symptoms. Future directions in analyzing the described surgical technique may be to determine the biomechanical strength and clinical effectiveness of a single-level L5-S1 fusion, in lieu of a multilevel fusion with rostral extension to L-4. Furthermore, the strength of this spinal construct may obviate the need for supplemental external orthosis in the postoperative period.

\section{Conclusions}

We have reported a single case of transsacral screw fixation construct for the treatment of high-grade spondylolisthesis in an adolescent with clinically and radiographically acceptable results. This technique should be studied further, and its use should be considered on a case-by-case basis based on patient anatomy. 


\section{References}

1. Amiot LP, Lang K, Putzier M, Zippel H, Labelle H: Comparative results between conventional and computer-assisted pedicle screw installation in the thoracic, lumbar, and sacral spine. Spine (Phila Pa 1976) 25:606-614, 2000

2. Bagó J, Pérez-Grueso FJ, Les E, Hernández P, Pellisé F: Minimal important differences of the SRS-22 Patient Questionnaire following surgical treatment of idiopathic scoliosis. Eur Spine J 18:1898-1904, 2009

3. Blanco JS, Sears CJ: Allograft bone use during instrumentation and fusion in the treatment of adolescent idiopathic scoliosis. Spine (Phila Pa 1976) 22:1338-1342, 1997

4. Bollini G, Jouve JL, Launay F, Glard Y, Jacopin S, Blondel B: High-grade child spondylolisthesis: a custom-made canulated screw to treat the so-called double instability. Orthop Traumatol Surg Res 97:179-185, 2011

5. Bosworth DM, Fielding JW, Demarest L, Bonaquist M: Spondylolisthesis; a critical review of a consecutive series of cases treated by arthrodesis. J Bone Joint Surg Am 37A:767-786, 1955

6. Bouyer B, Bachy M, Courvoisier A, Dromzee E, Mary P, Vialle R: High-grade lumbosacral spondylolisthesis reduction and fusion in children using transsacral rod fixation. Childs Nerv Syst 30:505-513, 2014

7. Boxall D, Bradford DS, Winter RB, Moe JH: Management of severe spondylolisthesis in children and adolescents. J Bone Joint Surg Am 61:479-495, 1979

8. Bradford DS, Gotfried Y: Staged salvage reconstruction of grade-IV and V spondylolisthesis. J Bone Joint Surg Am 69:191-202, 1987

9. Burkus JK, Gornet MF, Schuler TC, Kleeman TJ, Zdeblick TA: Six-year outcomes of anterior lumbar interbody arthrodesis with use of interbody fusion cages and recombinant human bone morphogenetic protein-2. J Bone Joint Surg Am 91:1181-1189, 2009

10. Burkus JK, Lonstein JE, Winter RB, Denis F: Long-term evaluation of adolescents treated operatively for spondylolisthesis. A comparison of in situ arthrodesis only with in situ arthrodesis and reduction followed by immobilization in a cast. J Bone Joint Surg Am 74:693-704, 1992

11. Carragee EJ: Single-level posterolateral arthrodesis, with or without posterior decompression, for the treatment of isthmic spondylolisthesis in adults. A prospective, randomized study. J Bone Joint Surg Am 79:1175-1180, 1997

12. Cheung EV, Herman MJ, Cavalier R, Pizzutillo PD: Spondylolysis and spondylolisthesis in children and adolescents: II. Surgical management. J Am Acad Orthop Surg 14:488498, 2006

13. Copay AG, Glassman SD, Subach BR, Berven S, Schuler TC, Carreon LY: Minimum clinically important difference in lumbar spine surgery patients: a choice of methods using the Oswestry Disability Index, Medical Outcomes Study questionnaire Short Form 36, and pain scales. Spine J 8:968-974, 2008

14. Fredrickson BE, Baker D, McHolick WJ, Yuan HA, Lubicky JP: The natural history of spondylolysis and spondylolisthesis. J Bone Joint Surg Am 66:699-707, 1984

15. Glassman S, Gornet MF, Branch C, Polly D Jr, Peloza J, Schwender JD, et al: MOS short form 36 and Oswestry Disability Index outcomes in lumbar fusion: a multicenter experience. Spine J 6:21-26, 2006

16. Harroud A, Labelle H, Joncas J, Mac-Thiong JM: Global sagittal alignment and health-related quality of life in lumbosacral spondylolisthesis. Eur Spine J 22:849-856, 2013

17. Johnsen LG, Hellum C, Nygaard OP, Storheim K, Brox JI, Rossvoll I, et al: Comparison of the SF6D, the EQ5D, and the Oswestry disability index in patients with chronic low back pain and degenerative disc disease. BMC Musculoskelet Disord 14:148, 2013
18. Kamimura M, Ebara S, Itoh H, Tateiwa Y, Kinoshita T, Takaoka K: Accurate pedicle screw insertion under the control of a computer-assisted image guiding system: laboratory test and clinical study. J Orthop Sci 4:197-206, 1999

19. Kumar R, Niall D, Walsh A, Khalilullah K, McCormack D: Spina bifida occulta in isthmic spondylolisthesis: a surgical trap. Eur Spine J 11:159-161, 2002

20. Lamberg T, Remes V, Helenius I, Schlenzka D, Seitsalo S, Poussa M: Uninstrumented in situ fusion for high-grade childhood and adolescent isthmic spondylolisthesis: longterm outcome. J Bone Joint Surg Am 89:512-518, 2007

21. Larson AN, Santos ER, Polly DW Jr, Ledonio CG, Sembrano $\mathrm{JN}$, Mielke $\mathrm{CH}$, et al: Pediatric pedicle screw placement using intraoperative computed tomography and 3-dimensional image-guided navigation. Spine (Phila Pa 1976) 37:E188E194, 2012

22. Lusskin R: Pain patterns in spondylolisthesis. A correlation of symptoms, local pathology and therapy. Clin Orthop Relat Res 40:123-136, 1965

23. Mason A, Paulsen R, Babuska JM, Rajpal S, Burneikiene S, Nelson EL, et al: The accuracy of pedicle screw placement using intraoperative image guidance systems. J Neurosurg Spine 20:196-203, 2014

24. Merloz P, Tonetti J, Eid A, Faure C, Lavallee S, Troccaz J, et al: Computer assisted spine surgery. Clin Orthop Relat Res (337):86-96, 1997

25. Meyerding HW: Spondylolisthesis: surgical treatment and results. J Bone Joint Surg Am 25:65-77, 1943

26. Molinari RW, Bridwell KH, Lenke LG, Baldus C: Anterior column support in surgery for high-grade, isthmic spondylolisthesis. Clin Orthop Relat Res (394):109-120, 2002

27. Muschik M, Zippel H, Perka C: Surgical management of severe spondylolisthesis in children and adolescents. Anterior fusion in situ versus anterior spondylodesis with posterior transpedicular instrumentation and reduction. Spine (Phila Pa 1976) 22:2036-2043, 1997

28. Myles RT, Fong B, Esses SI, Hipp JA: Radiographic verification of pedicle screw pilot hole placement using Kirshner wires versus beaded wires. Spine (Phila Pa 1976) 24:476480, 1999

29. Ota H: [Spondylolysis: familial occurrence and its genetic implications.] Nippon Seikeigeka Gakkai Zasshi 41:931941, 1967 (Jpn)

30. Peterson JB, Wenger DR: Asymmetric spondylolisthesis as the cause of childhood lumbar scoliosis--can new imaging modalities help clarify the relationship? Iowa Orthop J 28:65-72, 2008

31. Piwnica A, Cuillo JC: Contribution á l'exploration fonctionnelle du rachis. Analyse des contraintes par la méthode protoélastique. Ann Chir 12:1111-1121, 1958

32. Poussa M, Schlenzka D, Seitsalo S, Ylikoski M, Hurri H, Osterman K: Surgical treatment of severe isthmic spondylolisthesis in adolescents. Reduction or fusion in situ. Spine (Phila Pa 1976) 18:894-901, 1993

33. Rengachary SS, Balabhandra R: Reduction of spondylolisthesis. Neurosurg Focus 13(1):E2, 2002

34. Santos ER, Ledonio CG, Castro CA, Truong WH, Sembrano JN: The accuracy of intraoperative $\mathrm{O}$-arm images for the assessment of pedicle screw postion. Spine (Phila Pa 1976) 37:E119-E125, 2012

35. Saraste H: Long-term clinical and radiological follow-up of spondylolysis and spondylolisthesis. J Pediatr Orthop 7:631-638, 1987

36. Sarwahi V, Suggs W, Wollowick AL, Kulkarni PM, Lo Y, Amaral TD, et al: Pedicle screws adjacent to the great vessels or viscera: a study of 2132 pedicle screws in pediatric spine deformity. J Spinal Disord Tech 27:64-69, 2014

37. Sayama C, Willsey M, Chintagumpala M, Brayton A, Briceño V, Ryan SL, et al: Routine use of recombinant human 
bone morphogenetic protein-2 in posterior fusions of the pediatric spine and incidence of cancer. $\mathbf{J}$ Neurosurg Pediatr 16:4-13, 2015

38. Sembrano JN, Santos ER, Polly DW Jr: New generation intraoperative three-dimensional imaging $(\mathrm{O}$-arm) in 100 spine surgeries: does it change the surgical procedure? J Clin Neurosci 21:225-231, 2014

39. Smith MD, Bohlman HH: Spondylolisthesis treated by a single-stage operation combining decompression with in situ posterolateral and anterior fusion. An analysis of eleven patients who had long-term follow-up. J Bone Joint Surg Am 72:415-421, 1990

40. Van de Kelft E, Costa F, Van der Planken D, Schils F: A prospective multicenter registry on the accuracy of pedicle screw placement in the thoracic, lumbar, and sacral levels with the use of the O-arm imaging system and StealthStation Navigation. Spine (Phila Pa 1976) 37:E1580-E1587, 2012

41. Watkins MB: Posterolateral fusion in pseudarthrosis and posterior element defects of the lumbosacral spine. Clin Orthop Relat Res 35:80-85, 1964

42. Wiltse LL, Jackson DW: Treatment of spondylolisthesis and spondylolysis in children. Clin Orthop Relat Res (117):92100,1976

43. Wiltse LL, Newman PH, Macnab I: Classification of spon- dylolisis and spondylolisthesis. Clin Orthop Relat Res (117):23-29, 1976

44. Zendrick MR, Ibrahim K: Pedicle screw fixation, in Weinstein SL (ed): Pediatric Spine Surgery, ed 2. Philadelphia: Lippincott, Williams \& Wilkins, 2001,pp 493-514

\section{Disclosures}

The authors report no conflict of interest concerning the materials or methods used in this study or the findings specified in this paper.

\section{Author Contributions}

Conception and design: Jea. Acquisition of data: Palejwala, Fridley. Analysis and interpretation of data: Palejwala, Fridley. Drafting the article: Palejwala, Fridley. Critically revising the article: Jea. Reviewed submitted version of manuscript: Jea. Administrative/technical/material support: Jea. Study supervision: Jea.

\section{Correspondence}

Andrew Jea, Division of Pediatric Neurosurgery, Texas Children's Hospital, Department of Neurosurgery, Baylor College of Medicine, 6621 Fannin St., CCC 1230.01, 12th Fl., Houston, TX 77030.email: ahjea@texaschildrens.org. 